Como una tradición de la ceremonia de graduación de especialistas de la Facultad de Medicina de la Fundación Universitaria de Ciencias de la Salud. se ha invitado a una personalidad académica del país para que dirija unas palabras a los graduandos y a los asistentes en general. En la ceremonia del día 4 de Febrero de 2001 tuvimos el honor de contar con la presencia de la doctora Patricia Martínez Barrios. Directora General del ICFES y el siguiente es el texto completo de su intervención.

\title{
Invitación al servicio y al liderazgo, a raíz de la graduación de un grupo de especialistas
}

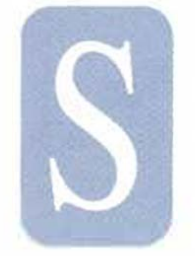

on muchas las ideas que rondaron mi pensamiento cuando llegó al ICFES la invitación a participar en esta ceremonia de graduación de especialistas de la Facultad de Medicina de la Fundación Universitaria de Ciencias de la Salud, acto que celebramos en el Auditorio Guillermo Fergusson. Esta ceremonia coincide con la muy reciente aprobación de la reforma estatutaria, aprobada por resolución 3537 de 28 de diciembre de 20(0), y notificada a la institución el pasado 26 de enero. O sea, es una ocasión muy adecuada para alegrarse por este nuevo paso que busca adecuar lo jurídico a la vida y a las necesidades de la institución y es una oportunidad, ciertamente, para felicitar, de un lado, a los directivos por mantener actualizada la Fundación a las exigencias actuales y, por otro, para dar la enhorabuena a quienes concluyen una especialización en la que tienen cifiadas sus esperanzas profesionales.

Por todo esto, permitanme, doctores Roberto Jaramillo Uricoechea, Rector de la Institución y Gonzalo López Escobar, Jefe de Posgrados e Internado, al igual que las demás directivas de esta Alma Mater y del Hospital de San José, hacer un sincero reconocimiento en estos graduandos a toda una vida institucional de servicio a la nación, a la medicina y, por sobre todo, a la vidahumana.

La medicina nacional alberga más especialistas gracias a la gestión de un grupo de profesionales que hace ya muchos años, en un acto de audacia y con el anhelo de contribuir a mejorar las condiciones de salud de los colombianos, empujjaron desde lo más profundo de las dificultades una facultad como la que hoy existe. El prestigio académico alcanzado como programa de alta calidad ha sido un sincero reconocimiento a su coherencia. La Fundación Universitaria de Ciencias de la Salud trabaja incansablemente para responder a los desafíos de su misión cuando dice que toma la responsabilidad de la formación integral de los profesionales de salual en los niveles básicos y avanzados, para que contribuyan con su liderazgo al desarrollo de la profesión y al mejoramiento de! nivel de vida de la población colombiana.

Los resultados no pueden ser más satisfactorios: el conjunto de programas de especialización en las diversas áreas de la salud tiene una excelente demanda por los profesionales de pregrado y el profesorado es su principal carta de presentación. Podemos decir que, además de brillantes profesionales, buscan ser maestros, conscientes de dar la respuesta positiva a la afirmación de Ermest Boyer según la cual un cirujano mediocre lastima una persona a la vez, mientras que un maestro mediocre lastima a toda una generación.

No sería lógico no compensar este esfuerzo y dedicación. Así lo ha visto el ICFES, consciente de la importancia de fomentar y defender los principios básicos de la gestión educativa de calidad. No podría el ICFES 
hacer menos, al encontrar motivos suficientes para ratificar a la Fundación Universitaria de Ciencias de la Salud en la senda de calidad deseada por sus directivas.

No quisiera desaprovechar esta oportunidad de dirigirme a ustedes para invitar a este exquisito grupo de profesionales a reflexionar sobre el reto personal, social, nacional y humano que sus integrantes tienen ahora como especialistas. Colombia requiere de formación profesional de primerísimo nivel, con la que ustedes ya cuentan, pero también con voluntad, compromiso y liderazgo para que el ejercicio de la medicina, en coherencia con sus bases primigenias, corresponda a la pasión y la vocación hecha oficio.

Sin esos atributos personales, que conforman el talante propio del verdadero profesional de la salud, no se podría alcanzar esa posición de servicio a la comunidad. Sería como aspirar, como por arte de magia, a que el ascenso en el conocimiento, manifestado en los títulos que hoy se entregan con gusto, representara sólo la posibilidad de ascender social y económicamente.

Porque ser médico en Colombia significa decirle sí a la vida en una cultura marcada por la violencia: significa, en respeto al Derecho Internacional Humanitario y como lógico devenir de la tolerancia, velar por la salud de cualquier persona; significa ser pedagogos y contribuir a concientizar a la población más vulnerable acerca de la importancia de cuidar su vida, de prevenir la enfermedad, porque sin dinero hay esperanza, sin tierra hay manos para trabajar, sin trabajo hay acompañamiento y solidaridad y sin educación hay sueños; pero, sin salud, es muy difícil pensar en un futuro. Abraham Lincoln decía que no se ayuda a los hombres en forma permanente si se hace por ellos lo que deberían y podrían hacer por ellos mismos.

Ser médico en Colombia significa el reto de formarse permanentemente, para dar respuesta a los desafíos de la ciencia y, fundamentalmente, para que la ignorancia, más allá de las dificultades logísticas, económicas o de procedimientos, no gane la batalla a la vida. Y, finalmente, significa el reto, consigo mismos, de llevar a la práctica profesional, el orgullo personal de hacer de la medicina una de las más hermosas manifestaciones profesionales del servicio, de la solidaridad y del compromiso con la comunidad que ha hecho posible este triunfo académico. Y cuando hablo de servir me estoy refiriendo a la acción generosa, esforzada y perseverante de ejercer la profesión y la especialidad en función permanente de construir sociedad.

Sé que muchas de estas reflexiones ya han sido hechas por ustedes, y sé que esta Institución se ha preocupado por incentivar el estudio y la vivencia ética de la profesión. No obstante, el ejercicio laboral conlleva una serie de dilemas que no siempre estamos capacitados para afrontar con suerte. Pero nos ayuda repetirnos, día a día, frente a cada paciente y a cada intervención profesional, que la razón de ser del ejercicio profesional del médico es la vida; que ningún motivo puede justificar la acción sin calidad y que, por encima de tos sentimientos personales, está el servicio profesional. Retos no siempre fáciles, pero satisfactorios al cumplir. Sé que ustedes comparten conmigo estas ideas.

No quiero alargarme más en estas consideraciones. Sólo quiero -al comprobar que la ceremonia de hoy es fruto de la inteligencia, la creatividad, la férrea voluntad y el liderazgo-, recordar cómo en esta institución parece haberse hecho realidad la invitación que alguna vez hizo Ernesto Sábato a detenerse a pensar en la grandeza a la que todavía podemos aspirar si nos atrevemos a valorar la vida de otra manera. Les pido, decía el literato, ese coraje que nos sitúa en la verdadera dimensión del hombre. Todos, una y otra vez nos doblegamos. Pero hay algo que no falla y es la convicción de que -únicamente-los valores del espíritu nos pueden salvar de este terremoto que amenaza la condición humana.

Creo, y estas ya son palabras mías, que el empeño y la tenacidad de los integrantes de la Fundación Universitaria de Ciencias de la Salud hacen honor al coraje de que habla el escritor. Muchas gracias y un sincero abrazo de felicitación a cada uno de ustedes.

Patricia Martínez Barrios Directora General ICFES 